Media Industries $5.1(2018)$

\title{
Negotiating State and Copyright Territorialities in Overseas Expansion: The Case of China's Online Video Streaming Platforms ${ }^{1}$
}

\author{
Elaine Jing Zhao ${ }^{2}$ \\ UNIVERSITY OF NEW SOUTH WALES \\ jing.zhao [AT] unsw.edu.au
}

\begin{abstract}
:
This article uses China's online streaming platforms as a typical case of the overseas expansion of digital entertainment media. It begins with an overview of the evolution of the online video industry in China, which has become formalized and consolidated over the past decade, before directing attention to the often informal cross-border access to mainland digital platforms among diasporic audiences. The article then examines platform-initiated expansion with a detailed analysis of the Baidu-owned online streaming platform iQiyi's entry into the Taiwanese market. By analyzing the regulatory dilemma over market entry, the complexities of negotiating windows in multimarket, and multimedia distribution involving varied business models and modes of access, the article highlights the challenges of negotiating multiple forms of territoriality. It also reveals the place of local and regional partnerships in such outbound trajectories.
\end{abstract}

Keywords: Territoriality, Regulation, Copyright, Geoblocking, Streaming, Distribution, China, iQiyi

China's communications industry has expanded rapidly since the early 2000s. The internet has brought countless new players, many of which are commercially driven. From a flotilla of startups to motherships including Baidu, Alibaba, and Tencent (collectively known as BAT), digital media service providers have proliferated. Largely supported by domestic, and sometimes transnational, private capital, these enterprises are a different breed than state-owned media conglomerates. Yet at the same time, they benefit from the state's 
two-pronged approach to the internet, where its relentless push to develop the internet as the new engine of growth paradoxically parallels its persistent attempt at blocking the activities of international internet giants such as Google, Twitter, YouTube, and Facebook.

Since late 1990s, information communication technologies in general, and the internet in particular, have been crucial to the state's attempts to stimulate economic development. China now has the world's largest internet population. Internet industries' contribution to growth in China is growing, accounting for 6.9 percent of overall gross domestic product (GDP) in 2016, 1.5 percentage points higher than the United States. ${ }^{3}$ Apart from its growing scale, the internet underpins the state's ambition to achieve a more sustainable model of growth against the broader backdrop of economic restructuring. Specifically, the state aims to leverage the potential of the internet to revitalize existing industries and foster innovation and consumption. The unveiling of the Internet Plus blueprint in 2015 further illustrates the state's intention to create synergies between the internet and other sectors. Media industries, and cultural and creative industries more broadly, are part of this picture. This new plan has emanated from the earlier call for the convergence of technology and culture, a policy discourse prominent in media system reform. ${ }^{4}$

Despite being a strategic initiative for economic restructuring and development, the internet is a double-edged sword for the state. The imperative to block internet players with near-global reach, such as Facebook and Google, derives from the need to control information flows and construct an indigenous internet. The authoritarian regime's combined approach of embracing and adjusting to the inevitable changes brought by digital communications is characterized by Rebecca MacKinnon as "networked authoritarianism." This model allows homegrown internet enterprises to foster in a domestic market because they are shielded from international competitors.

The politics of protection does not mean China remains insular. In fact, China's reintegration into the global economy has had significant impacts on its communications industry. First, while much of the industry is "off limits" to foreign players, a growing number of collaborators are investing in domestic media companies. This is particularly germane to digital media platforms, which have witnessed collaborations in content licensing and coproduction. ${ }^{6}$ These collaborations are enriching Chinese people's media diet.

Although the internet has long been a fermenting ground for copyright infringment, copyright management has begun to assume an increasingly significant role. Digital platforms spend fortunes not only on content licensing but also on original content creation. Copyright protection-and enforcement-has become increasingly important. This enforcement is as much a response to compliance pressure in the post-World Trade Organization (WTO) era as an attempt at formalizing and growing internet industries. The State Council emphasized the importance of IPR (intellectual property rights) protection in the emerging internet industries during the Thirteenth Five-Year Plan period (2016-20), ${ }^{7}$ linking to the National Intellectual Property Strategy established in $2008,{ }^{8}$ and the State Council's (2015) action plan to further implement the strategy from 2014 to $2020 .{ }^{9}$ The plan outlines the goal of building "a strong IPR nation" by promoting the creation and utilization of intellectual property and strengthening IPR protection. Apart from promoting "intellectual property-intensive industries" to drive industry restructuring in the domestic economy, the plan aims to support the overseas expansion of enterprises. 
The mainland market is no longer the only turf the homegrown digital platforms are coveting. While predominantly driven by commercial interests, outgoing attempts (i.e., "going out") align with the state's hope to extend its cultural influence across national borders, as other papers in this special section attest. Existing literature on Chinese media's overseas expansion, however, focuses predominantly on national champions, such as China Central Television (CCTV), Xinhua News Agency, and Confucius Institutes. These initiatives have so far reaped little fruit. For David Shambaugh, ${ }^{10}$ China's global presence is more broad than deep, and this has led him to characterize China as a "partial power." In the broader context whereby information and communication technologies and China constitute "two poles of growth" in today's transnational capitalism, ${ }^{11}$ digital platforms' outward expansion warrants closer scrutiny. As they venture into new territories, questions remain as to what strategies they are adopting and how smooth their journeys are.

This article depicts China's online streaming platforms as a typical case of the overseas expansion of digital entertainment media. It begins with an overview of the evolution of the online video industry in China, which has become formalized and consolidated over the past decade. It explains how copyright has become firmly grounded in the strategic plans of leading streaming platforms as a result of international pressure, state regulation, industry selfregulation, and market competition in the post-WTO era. Then the article directs attention to the often informal cross-border access, largely among diasporic communities, to China's digital platforms which not only offer Chinese content but also increasingly invest in licensing deals and production partnerships with overseas copyright owners. This often-hidden mode of access and connectivity illuminates the informal process of China's digital platforms as they extend their reach across borders. The article then focuses on the Baidu-owned online streaming platform iQiyi's entry into the Taiwanese market. By analyzing the regulatory dilemma over market entry, the complexities of negotiating windows in multiple markets, and multimedia distribution involving varied business models and modes of access, it highlights the territorial challenges digital platforms face when they seek overseas expansion. Finally, it also shows how local and regional partnerships play an important role in outbound trajectories.

\section{Online Video Streaming in Mainland China}

Online video sites in Mainland China have been shielded from head-on competition with global platforms. The protection is a result of the state's decision to block international sites by constructing the Great Firewall, a powerful internet censorship apparatus. Such state-led geoblocking reflects the sovereign role of the state in its governance of the increasingly balkanized internet, as captured by the term "splinternet." Geoblocking, a key mechanism of regulating content flows based on spatial dimensions, sets boundaries of access. In China, this technological exclusionist project is largely driven by political concerns, that is, the state filters what it considers as "threatening." In official language, these blocking mechanisms are designed to maintain social order and protect socialist values. The net effect is to shelter born-in-China digital platforms within the mainland market, allowing them to grow into dominant destinations for information, communication, and entertainment. 
The early days of online screen consumption inherited the shadowy informal zone of consumption exploited by its predecessors. Most notably represented by pirated VCDs and DVDs offered by street vendors or legitimate video stores, the informal market fills the gap in a market characterized by restrictive censorship, less appealing domestic offerings, and strict import quotas of overseas content. Technological advancement witnessed the rise of applications such as eDonkey, BT China, VeryCD, and Xunlei dedicated to screen content downloading based on peer-to-peer file sharing protocols. These service providers, together with fansubbing communities, acted as cultural intermediaries to address unmet consumer demand.

As an ownership-oriented culture gradually gave way to more access-based, on-demand consumption around the turn of the millennium, video on-demand services emerged in China. Initially, websites transformed into video content/service providers of value-added service portals developed by major telecom corporations before being overshadowed by venture capital-backed online video platforms by the mid-2000s. Apart from online TV platforms such as PPTV and PPS, many streaming platforms started out with a video-sharing model based on user-generated content. Best represented by Tudou, 56, ku6, and Youku, these platforms constituted a parallel universe to YouTube. The new online space had its deep roots in amateur practices, from producing creative works to uploading infringing content. Vernacular creativity manifested itself in a wide range of user-generated videos. From the light-hearted to the more socially and politically critical, some of these videos became huge Internet phenomena, and this is still the case. ${ }^{2}$ Despite the social-cultural value of amateur productions, their mixed quality, copyright infringement risks, and enormous bandwidth costs, together with attendant diseconomies of scale, became problematic. The initial enthusiasm toward user-generated content thus cooled down.

As venture capital-backed platforms adjusted content strategies, the state exerted influence on the industry. The online space has come under the purview of the state since 2008, following the enforcement of Administrative Provisions on Internet Audio-Visual Program Service (the Provisions). ${ }^{13}$ Apart from appeasing the international community of copyright holders and extending domestic ideological control online, the Provisions signaled the state's intention to capture the growth in the online video market. ${ }^{14}$ The licensing regulation outlined in the Provisions established the entry barrier to a formerly undisciplined "wild west." Further enforcement campaigns targeting infringing and "unhealthy" content accelerated the industry shakeout and pushed streaming platforms into a voracious pursuit of copyright. This resulted in the skyrocketing licensing costs in the ensuing years, which has further consolidated the power of market players. Pressure from both domestic and international copyright owners has in turn led to fierce competition among streaming platforms.

The increasing focus on content production illustrates the key role of copyright as a strategic resource to enhance competitiveness. More recently, streaming platforms have adopted a multipronged strategy to build up a content matrix including both commissioned production and in-house production. ${ }^{15}$ Meanwhile, the growing market has seen increasing crossborder collaborations in original programming including format adaptation. Streaming platforms are not only distributing but also producing and nurturing new genres and formats. As a result of this competition, platforms have increasingly resorted to geoblocking to manage access to copyrighted content in multiple territories. 
Within over a decade, online screen content has become a mainstay of the cultural repertoire in China. Online video platforms are investing in content to appeal to the close to six hundred million and increasing users. Users aged between twelve and thirty-four years account for almost 60 percent of all online video viewers ${ }^{16}$; younger generations are therefore the primary target. Digital platforms have transformed viewing experiences, which is now characterized as "connected viewing", where social media and user interactions become intimately entwined with multiplatform viewing interfaces. At the same time, through mergers and acquisitions, the internet giants Baidu, Alibaba, and Tencent are dominating the online streaming market in China, accounting for over 50 percent of the market share by mid-2016. ${ }^{18}$

\section{Geoblocking Circumvention and Hidden Outgoing Flows}

Although both the state and market players employ geoblocking strategies, geoblocking circumvention is a common practice among internet users. Existing scholarship focuses predominantly on circumventing state and corporate censorship to reach content blocked or unavailable in China. Aynne Kokas, ${ }^{19}$ for example, identifies a "blended public sphere," where social media conversations about access counter the rigorously controlled Chinese media landscape. Jinying $\mathrm{Li}^{20}$ discusses the technopolitics of the firewall in video cultures and points out that wall-crossing profoundly politicized almost all aspects of Chinese cyber life even when people mostly do it for entertainment purposes.

What has been less discussed is how diasporic Chinese communities are increasingly returning to the Chinese internet. This has many precedents in media consumption. Diasporic populations have a long history of seeking out screen content in their native language via specialist public broadcasting television networks, pay-TV channels with a package of Chinese-language content, or DVDs purchased from video stores in China towns or shared among friends and relatives. $^{21}$ The media space of diasporic communities constitutes geolinguistic regions defined, to a large extent, by linguistic, cultural, and historic connections which transcend physical space. ${ }^{22}$ Apart from content from Mainland China, productions from Hong Kong, Taiwan, and Korea are often available in various packages. The arrival of the internet, however, has changed consumption patterns. In his discussion of how Chinese television content goes out, Michael Keane ${ }^{23}$ posits that online platforms are aggregating a form of Chinese soft power. While it might not be influencing foreign audiences, at least Chinese communities globally are "reconnected" to Chinese culture. Moreover, many Chinese TV stations have deployed official accounts on YouTube, which has become a popular destination for overseas Chinese to consume Chinese-language content for free. The irony is evident; born-in-China market players are distributing content on sites such as YouTube for international reach, while those very sites are blocked in China. Apart from media organizations, various parties facilitate such transborder circulation of content, including fans, piracy entrepreneurs, and copyright owners. Thus, the geopolitics of internet governance is imbricated with both official and unauthorized flows of content across borders.

When diasporic audiences attempt to access content on mainland streaming platforms, they are often greeted with the line, "This video is only available in mainland China," a reflection of a wider trend of employing content geoblocking as a mode of regulation and 
enforcement. ${ }^{24}$ Specifically, copyright owners and streaming platforms include geoblocking in licensing contracts to comply with territorial limitations of the license. Thus, access to licensed content on streaming platforms in China necessitates a detour-through geoblocking circumvention-as a result of those territorially defined rights. As Benjamin Burroughs and Adam Rugg ${ }^{25}$ emphasize, the internet not only acts as a vehicle of mobility, transporting users to other places, but also, through the use of geofencing circumvention tools, changes the place users start at. In the words of Ira Wagman and Peter Urquhart, ${ }^{26}$ "the fact remains that where you access the internet says a lot about what kind of internet you experience." Diasporic Chinese exploit a diversified range of circumvention tools, including VPNs (virtual private networks), DNS (domain name system) proxies, and location-masking browser extensions to access content on Chinese streaming platforms. Tutorials abound in diaspora forums to educate less technologically sophisticated users about the ways to access geoblocked content.

As overseas users reconfigure their viewing experience with circumvention tools, streaming platforms such as Youku Tudou, iQiyi, and Tencent Video provide a wide range of licensed content for free, thanks to a business model predominantly based on advertising. Notably, diasporic audiences are seeking not only Chinese-language content on streaming platforms but also licensed content in other languages. Such premium content ranges from Hollywood films to British, American, and South Korean drama series, as well as domestic productions. More recently, however, the platforms' drive to seek revenue from paid subscriptions has complicated the scenario. This strategy requires digital platforms to manage access to content in multiple territories by taking into consideration diversifying business models.

\section{The Case of iQiyi in Taiwan}

\section{State Territoriality and Market Entry Barriers}

While China's streaming platforms are noticing digital content "going global" formally and informally, iQiyi has strategically deployed its presence in Taiwan. As the forerunner of overseas expansion among mainland steaming platforms, iQiyi launched its Taiwan site in March 2016, joining local platforms such as CGTV Video and CatchPlay, as well as the global player Netflix to compete for the local market. The Taiwanese site offers eleven channels: theater, movies, variety, animation, entertainment, comedy, children, trailers, travel, documentaries, and iQiyi productions. Users can view advertising-supported content for free or choose from a three-tier subscription plan to access premium content and skip advertising. A monthly subscription costs NT\$239 (roughly RMB 48), slightly cheaper than the NT\$270 charged by Netflix and more than double the cost in the mainland.

Taiwan holds much appeal to the platform for various reasons. First, Taiwanese spend 7.8 hours per week watching video on demand on the internet, 1.8 hours higher than the global average, as revealed by an Ericsson report issued in November $2015 .{ }^{27}$ Second, according to Gong $\mathrm{Yu}$, founder and CEO of iQiyi, as the second largest Chinese-speaking market after Mainland China, Taiwan offers significant market potential as the platform expands overseas. Moreover, local consumption of productions from the mainland has been on the rise in recent years, through authorized and unauthorized modes of access. Third, existing 
ties between Taiwan and the mainland in screen production and distribution provide numerous collaboration opportunities with local partners. In the past, Taiwan was a trusted cultural intermediary in passing on second-hand knowledge from overseas production centers. Taiwanese screen products appealed to mainland audiences as they symbolized modernity and bore resemblance to American and Japanese popular culture. ${ }^{28}$ The affinity with Taiwan has led to many "Taiwan-inspired" screen products in the mainland, especially in the domain of variety shows and idol drama. However, the industry in Taiwan has experienced a decline in recent years, with continuously dwindling production budgets. This decline has much to do with the economic slowdown, precipitating a sharp drop in advertising values in an already fragmented market resulting from the politically motivated deregulation of the 1990s, and the risk-averse mentality among cable channels in the face of intense competition. I have discussed elsewhere how Taiwan's status as a knowledge broker has weakened and how collaboration across the strait has become reconfigured in recent years, as content production in the mainland has moved from informal imitation or copycats to format trade, adaptation, and original programming. ${ }^{29}$ In the case of iQiyi, collaborations with independent production firms and celebrities in Taiwan are visible in its content strategies. ${ }^{30}$

The entry of iQiyi into the Taiwanese market, however, has not been smooth sailing. Its operation in Taiwan is reliant on the support of a local agent; the platform started its trial operation in November 2015 via a local intermediary OTT Entertainment Ltd. on a revenuesharing basis. This arrangement represents a necessary contingency. While iQiyi had hoped to set up a subsidiary, Taiwan's Investment Commission, in consultation with Taiwan's Ministry of Culture and its Mainland Affairs Council, rejected its application. Considering that Netflix was able to establish a local subsidiary in Taiwan, it is evident that long-standing cross-strait tensions mean that companies from the mainland face stricter investment legislations than other foreign-owned firms. According to Taiwan's Investment Commission, iQiyi submitted an application to establish a subsidiary as an "electronic information service provider" but actually intended to operate as an over-the-top (OTT) service for broadcasting entertainment content, a domain where Chinese investment is not allowed. ${ }^{31}$ Evidently, the platform's claim to be a service provider encountered challenges from the regulators, who scrutinized the platform as a content carrier instead. The perceived risk no doubt lies in the foreseeable entry of made-in-mainland content, including propaganda. In fact, as Wanning $\mathrm{Sun}^{32}$ points out, the purpose of the state's top priority to develop China's internet is to assist external propaganda. Taking into consideration Mainland China's strict approach to internet governance, the alarm bells rang even louder. The ideological influence exerted by the state over what transpires on the internet obviously extends beyond the border; this extension of PRC internet sovereignty is a concern because digital platforms like iQiyi are acting as the new "champions" of overseas expansion (see papers by Keane and Wu; Leong).

The regulatory barriers have arisen from a combination of factors: fear about the mainland's potential encroachment of local culture, media independence, and democracy; the concern over Taiwan's local industry and economic development; and persistent identity politics. ${ }^{33}$ To purchase goodwill from regulators, iQiyi has worked closely with local partners such as GTV, ETTV, and TTV to secure local content to build up its content library in Taiwan. Moreover, the platform has invested in commissioned content through collaboration with local production teams. This collaboration, however, has triggered opposing voices that point to the risk of increasing economic integration with the mainland and its associated 
political implications. In a broader context, Taiwanese nationalism and antagonism toward free trade and neoliberal globalization do exist within the society. ${ }^{34}$ Such tensions exist in parallel with the drawing power of the mainland market, evidenced not only in the increasing popularity of its screen content but also in the trend of creative migration across the border. ${ }^{35}$ As digital platforms in the mainland sail outward, they encounter regulatory challenges over market entry. Geopolitical tensions and identity politics further complicate matters. Despite market entry regulation, the presence of iQiyi has become a reality through willing collaborators in the local market.

The case of iQiyi in Taiwan shows the impact of territorial-based sovereignty on the development of internet businesses, which for some represents the long arm of the Chinese surveillance state. For Taiwan, the expansion of China's homegrown platforms beyond domestic borders inevitably raises ideological challenges. At the same time, the increasing pull of China's soft power is drawing Taiwan's own content industries into a forced marriage with Mainland Chinese partners. In an era of increasing diplomatic tensions, the overseas ambitions of communication platforms are not plain sailing.

\section{The Market Logic of Territoriality and the Complexity of Access}

Although state sovereignty remains an enduring power in regulating the internet, market actors pursue a different logic of territorialization to maximize profits. Apart from market segmentation and distribution, copyright regimes have become instrumental in creating territorialities in the digital market place ${ }^{36}$ Such regimes have become a central component of the online screen economy around the world. Conventionally, distributors segment global markets by platform and territory in rolling out content through a series of sequential release windows to engineer scarcity and maximize returns. ${ }^{37}$ Digitization of content and platforms, however, are disrupting traditional windowing models, raising questions in relation to exclusivity and timing. ${ }^{38}$ The threat of digital piracy, for example, has shortened release window periods. Both film and TV industries have experimented with the day-and-date approach, where content is released simultaneously across different geographic markets and various outlets and platforms. ${ }^{39}$ Different business models are also key considerations in maximizing the distribution value of content. ${ }^{40}$ An evident trend is that subscription video on-demand players typically require exclusive ownership of content for an extended period as they deploy their multinational presence. ${ }^{41}$

Apart from building up a library of local content by working closely with local partners, iQiyi exports drama series and variety shows made in the mainland, offers licensed movies from Hollywood majors, and rides on the pan-Asian phenomenon of Korean wave. The breakthrough of the site in Taiwan is credited to its exclusive license to distribute the Korean drama Descendants of the Sun (Taiyang de houyi, 태양의 후예). The disclosed licensing cost for the sixteen-episode series in China was unprecedentedly high for Korean drama, at approximately RMB 24 million (around US\$4 million), which is equivalent to about 40 percent of the show's production costs. ${ }^{42}$ And this is the figure for acquiring the rights for the mainland only. The Taiwan site receives its own annual budget from mainland headquarters and acquires rights separately.The fact that iQiyi secured the right to distribute the series owes much to increasing Sino-Korean media collaborations. The series was fully preproduced before airing by Seoul-based producer-distributor Next Entertainment World (NEW). The financing of the 
Descendants of the Sun received substantial support from the presale of Chinese rights to iQiyi, in large part due to the intermediary that connected NEW to iQiyi. The middleman is Zhejiang Huace Film \& TV (hereafter Huace), one of China's largest and most prolific TV drama, and increasingly film, production companies. The Hong Kong investment arm of Huace purchased a 15 percent stake in NEW for RMB 323 million (US\$52.65 million) in 2014 and became its second largest stakeholder. ${ }^{43}$ Such investment reflects the growing trend of Chinese capital pouring into the Korean entertainment industry. ${ }^{44}$ Meanwhile, Huace and iQiyi formed a joint venture called Huace iQiyi Film \& TV in 2014 to produce content to be streamed on iQiyi. The broader context is that streaming platforms in China are aiming for a bigger role in content production. Huace played a key role in connecting NEW and iQiyi: the former was looking to fund its production and the latter was seeking the next hit.

To secure best return on investment in content that is sourced from outside China, a wellconsidered multiterritory distribution strategy is vital. Apart from time, repeat consumption, and exclusivity, differential pricing needs to be factored into consideration. ${ }^{45}$ This is particularly pertinent to iQiyi at a time when it seeks to diversify its revenue streams. While advertising is still the dominant revenue source for iQiyi in the mainland, viewer subscription is the next frontier. According to Yang Xianghua, senior vice-president overseeing subscription services at iQiyi, the average revenue per subscription is twenty times more than the average advertising revenue per user; by converting 5 percent of its users to paying subscribers, the platform predicts subscription and advertising contributing equally to the total revenue. ${ }^{46}$ The platform has received a further pump-priming of US\$1.53 billion venture capital to support ongoing investment in content, particularly to drive original productions and paid subscriptions. ${ }^{47}$

In such context, the platform is adopting a paid subscription model in both the mainland and Taiwanese markets and leveraging its exclusive content to migrate users from its free service to its premium service. Pricing variances are then factored into distribution strategies to maintain the window between paying and non-paying viewers. In the case of Descendants of the Sun, while paying mainland subscribers of iQiyi can follow the series simultaneously as it is released on the South Korean broadcaster KBS (Korean Broadcasting System), nonpaying subscribers have to bear with a one-week delay. In Taiwan, nonpaying users could only watch the first six minutes of each episode, as in the case of other premium content on the site. Meanwhile, the platform gained a significant competitive advantage against ETTV (Eastern Television) in Taiwan, which lagged several months behind in broadcasting the show. The windowing strategy has been successful in driving the paid subscription model in Taiwan as well as in the mainland, with the number of total subscribers surpassing twenty million by June $2016 .{ }^{48}$

Both the market logic of territoriality and the state logic of territoriality in internet governance overlap to complicate one of the most crucial drivers of paid subscription: simultaneous release across multiple markets. Conventionally, Korean drama production functions on a live-shoot system, where the series starts airing after shooting the first few episodes, and then two episodes are produced weekly for the following week's broadcasting. ${ }^{49}$ This staggered production, to a large extent, results from uncertainty over domestic distribution prospects in South Korea. As independent production firms have to compete fiercely to 
land a distribution deal with one of the three terrestrial broadcasting stations, preproduction of the whole drama series is extremely risky. Moreover, a shortened filming process helps cut production costs. Although this approach raises the challenge of a tight shooting schedule, it allows production teams to respond to audience feedback on social media as the series is aired. ${ }^{50}$

Yet, the live-shoot approach found in Korean drama production is incompatible with the barrier foreign content faces in China, which has now been extended online. In September 2014, China's media watchdog the State Administration of Press, Publication, Radio, Film and Television (SAPPRFT) required streaming sites to register foreign films and television shows for approval in advance. ${ }^{51}$ Therefore, to achieve simultaneous release in multiple territories, including Mainland China, Korean dramas were preproduced for censorship clearance by SAPPRFT. Apart from gaining time to secure the green light from China's media regulator, completing production before airing allows time for subtitle production. By contrast, the live-shoot system usually results in a delay in the release of the subtitled version. With the Korean drama hit My Love from the Star (laizi xingxing de ni, 별에서온그대), for example, iQiyi released the original version first, followed by a subtitled version hours later. The seemingly small time lag, however, is a nontrivial issue for fans.

Although the release strategy boosted paid subscription in Taiwan, notable glitches in viewing experiences have arisen because of the territorial nature of copyright licensing and the lack of cross-border portability of digital content. In the case of Descendants of the Sun streaming on iQiyi Taiwan, the platform posted a message on Facebook on March 3, 2016, announcing the decision to temporarily remove the series off the Taiwanese site. The post cited copyright negotiations and geographic restrictions as the reason behind the decision. One week later, the platform posted another message to notify users of the return of the series and remind users in Taiwan that they must sign up as paying subscribers at the Taiwanese site instead of the mainland site to view the series.

The territorially delineated nature of copyright and variations in content libraries result in viewer frustration. Clearly, access is denied for users in Taiwan who sign up with mainland platforms. Some residents in Taiwan, however, intentionally circumvent geoblocking to sign up at the mainland site because of price or content discrepancy. Yet, unreliability of circumvention technologies are creating friction in viewing experiences. Furthermore, lack of content portability brings inconvenience to people frequently traveling between Taiwan and Mainland for holidays or business trips. Essentially, the conflict arises from the tension between the increasing mobility of populations and lack of content portability, as well as between geoblocking and the availability of streaming platforms in multiple territories.

The subscription options available at both sites further complicate matters. For paying subscribers registering at the Taiwan site, access to content exclusive to the Mainland is denied. While users outside of Mainland China can pay for the overseas subscription service, they do not have a clear idea of the content library they can access. The result is consumer resentment, as many feel tricked into the paid service by a misleading presentation of what content is available. iQiyi never indicates what is accessible where until the user hits the play button. In other words, while the mainland site offers the option of an overseas subscription, the 
territorial restrictions on its content library set up hidden geoblocks for overseas users. The platform's wish to profit off overseas viewership through paid subscription does not match the uneven geography of copyright.

This frustration then invites surreptitious access enabled by circumvention technologies. As the platform intends to diversify its revenue structure and moves to place an increasing amount of content behind its paywall, the site's capacity to earn subscription revenue from overseas users is intimately intertwined with the long-standing informal video cultures. Because Taiwan is only the first step of its expanding overseas trajectory, the platform is probably tolerating such informality with a view to achieving a wider scale of economic benefit down the road.

\section{Conclusion}

China's push to develop the indigenous internet while blocking international competitors has nurtured the state's "digital champions." Despite the state sovereignty over internet governance manifest in the politics of blockage, Mainland China's reintegration into the global economy has brought widespread changes to its media and communications industries. Digital platforms are witnessing increasing collaborations with overseas partners, an ascending role for copyright, and growing consumption from overseas, largely among diasporic communities. Such viewership is sometimes intimately bound up with informal access to geoblocked content.

As digital platforms start expanding into new frontiers, what unfolds is a process of negotiating with multiple publics and multiple forms of territoriality. The case of iQiyi discussed in this article is a telling example. The platform faces market entry barriers when local authorities exert sovereignty over internet control in the broader context of geopolitical tensions. Concerns arise over encroachment of local culture, media independence and democracy, impact on local industries, Taiwan's increasing economic integration with China, and its political implications. Digital platforms face more challenges as they negotiate windows in multimarket and multimedia distribution involving varied business models and modes of access. The process requires considerable negotiation with copyright owners, the sovereign state, and sometimes even adaptation of production models. Moreover, lack of content portability and discrepancy in content libraries further structure markets around territorialized logics associated with copyright regimes. As this creates frictions in viewing experiences, it encounters resistance, which paradoxically shows how informal video culture is feeding subscription-based video on demand. Overall, as digital platforms expand beyond the home territory, they meet challenges on different levels. Such challenges have much to do with the enduring role of the state in internet governance at the institutional level, multiterritory content distribution at the industry level, and informal modes of access across borders.

\footnotetext{
${ }^{1}$ Research for this article was funded through the Australian Research Council Discovery Project (DP170102176), titled Digital China: From Cultural Presence to Innovative Nation.
} 
${ }^{2}$ Elaine Jing Zhao is Lecturer in the School of the Arts and Media at the University of New South Wales. She has published widely on digital media and cultures, creative communities, informal media economies, and their social, cultural, and economic implications in transitional China. She is currently a Chief Investigator of an Australia Research Council-funded Discovery Project (DP170102176), which examines China's attempt to use "digital power" of the internet to achieve international recognition as an "innovation nation."

${ }^{3}$ China Daily, "China a Leader in Global Internet Market: Report," September 14, 2017, http://www.chinadaily.com.cn/business/tech/2017-09/14/content_31987721 .htm.

${ }^{4}$ Michael Keane and Elaine Jing Zhao, "The Reform of the Cultural System: Culture, Creativity and Innovation in China," in Cultural Policies in East Asia: Dynamics between the State, Arts and Creative Industries, ed. Lee Hye-Kyung and Lorraine Lim (NY: Palgrave Macmillan, 2014), 155-73.

${ }^{5}$ Rebecca MacKinnon, "Networked Authoritarianism in China and Beyond: Implications for Global Internet Freedom," Journal of Democracy 2 (2011): 32-46.

${ }^{6}$ See discussions on media collaborations between foreign and homegrown enterprises in Willing Collaborators: Foreign Partners in Chinese Media, ed. Michael Keane, Brian Yecies, and Terry Flew (London: Rowman \& Littlefield, 2018).

${ }^{7}$ China Daily, "China Makes Plans for Stronger IPR Protection," January 19, 2017, http://www.chinadaily.com.cn/business/2017-01/19/content_27999737.htm.

8 The State Council, "Notice of the State Council on Issuing the Outline of the National Intellectual Property Strategy," 2008, http://www.gov.cn/zwgk/2008-06/10/ content_1012269.htm.

${ }^{9}$ The State Council, "Action Plan for In-depth Implementation of National Intellectual Property Rights Strategy (2014 2020)," January 5, 2015, http://nipso.cn/onews .asp?id=24266.

${ }^{10}$ David Shambaugh, China Goes Digital: The Partial Power (Oxford: Oxford University Press, 2013).

${ }^{11}$ Dan Schiller, Digital Depression: Information Technology and Economic Crisis (Urbana: University of Illinois Press, 2014).

12 Paola Voci, China on Video: Smaller-Screen Realities (Oxon and NY: Routledge, 2010).

${ }^{13}$ SARFT, "Administrative Provisions on Internet Audio-Visual Program Service," September 29, 2017, http://www.sarft.gov.cn/articles/2007/12/29/200712291315 21450172.html.

${ }^{14}$ Elaine Jing Zhao and Michael Keane, "Between Formal and Informal: The Shakeout in China's Online Video Industry," Media, Culture E Society 6 (2013): 724-41.

${ }^{15}$ Ibid.; Elaine Jing Zhao, "Professionalization of Amateur Production in Online Screen Entertainment in China: Hopes, Frustrations and Uncertainties," International Journal of Communication 10 (2016): 5444-62.

${ }^{16}$ China Mainland Media Research Co. Ltd, "Young Viewers Become the Majority of Online Video Viewers," 2016, http://www.cmmrmedia.com/CMMRxinwen/_ zbfb_mld__nq_cwlspyhzybq_861861.html.

${ }^{17}$ Jennifer Holt and Kevin Sanson, "Mapping Connections," in Connected Viewing: Selling, Streaming and Sharing Media in the Digital Era, ed. Jennifer Holt and Kevin Sanson (NY: Routledge, 2014), 1-16. 
18 "2016 Report on China's Online Audiovisual Market Development: Online Video Users Reading 514 million," December 8, 2016, http://www.ce.cn/culture/ gd/201612/08/t20161208_18500732.shtml.

19 Aynne Kokas, "American Media and China's Blended Public Sphere," in Connected Viewing: Selling, Streaming, E Sharing Media in the Digital Era, ed. Jennifer Holt and Kevin Sanson (NY: Routledge, 2014), 144-57.

${ }^{20}$ Jinying Li, "China: The Techno-politics of the Wall," in Geoblocking and Global Video Culture, ed. Ramon Lobato and James Meese (Amsterdam: Institute of Network Cultures, 2016), 110-19.

${ }^{21}$ John Sinclair et al., "Chinese Cosmopolitanism and Media Use," in Floating lives: The Media and Asian Diasporas, ed. Stuart Cunningham and John Sinclair (St Lucia: University of Queensland Press, 2000), 1-34.

${ }^{22}$ John Sinclair, Elizabeth Jacka, and Stuart Cunningham, New Patterns in Global Television: Peripheral Vision (Oxford: Oxford University Press, 1996), 5.

${ }^{23}$ Michael Keane, "Disconnecting, Connecting, and Reconnecting: How Chinese Television Found its Way Out of the Box," International Journal of Communication 10 (2016): 5426-43.

${ }^{24}$ Trimble, Marketa, "Geoblocking, Technical Standards and the Law," in Geoblocking and Global Video Culture, ed. Ramon Lobato and James Meese (Amsterdam: Institute of Network Cultures, 2016), 54-63.

${ }^{25}$ Benjamin Burroughs and Adam Rugg, "Extending the Broadcast: Streaming Culture and the Problems of Digital Geographies," Journal of Broadcasting E Electronic Media 58 (2014): 365-80.

${ }^{26}$ Ira Wagman and Peter Urquhart, "This Content Is Not Available in Your Region: Geoblocking Culture in Canada," in Dynamic Fair Dealing: Creating Canadian Culture Online, ed. Darren Wershle, Coombe Rosemary, and Martin Zeilinger (Toronto, ON: University of Toronto Press, 2014), 124-32.

${ }^{27}$ Taipei Times, "iQiyi Enters Taiwanese Video-streaming Market," March 20, 2016, http://www.taipeitimes.com/News/biz/archives/2016/03/30/2003642734.

${ }^{28}$ Thomas Gold, "Go With Your Feelings: Hong Kong and Taiwan Popular Culture in Greater China," The China Quarterly 136 (1993): 907-25; Koichi Iwabuchi, Recentering Globalization: Popular Culture and Japanese Transnationalism (Durham and London: Duke University Press, 2002).

${ }^{29}$ Elaine Jing Zhao, "Collaboration Reconfigured: The Evolving Landscape of Entertainment TV Markets between Taiwan and Mainland China," Media International Australia 159, no. 1(2016): 53-62.

${ }^{30}$ Elaine Jing Zhao, "Cross-straits Online Collaboration: Multiple Publics and Intractable Institutions," in Willing Collaborators: Foreign Partners in Chinese Media, ed. Michael Keane, Brian Yecies, and Terry Flew (London and NY: Rowman \& Littlefield, 2018), 187-198.

31 Taipei Times, "Investment Commission Rejects iQiyi's Application," November 29, 2016, http://www.taipeitimes.com/News/biz/archives/2016/11/29/2003660181.

${ }^{32}$ Wanning Sun, "Slow Boat from China: Public Discourses behind the "Going Global" Media Policy," International Journal of Cultural Policy 21 (2015): 400-18.

${ }^{33}$ Zhao, "Cross-straits Online Collaboration." 
${ }^{34}$ Bowen Tseng, "The Sunflower Movement: The Spatiality of Discursive Axes," Reflection 27 (2014): 129-48; Chih-ming Wang, "The Future That Belongs to Us': Affective Politics, Neoliberalism and the Sunflower Movement," International Journal of Cultural Studies 2 (2017): 177-92.

${ }^{35}$ Zhao, "Collaboration Reconfigured."

${ }^{36}$ Cameran Ashraf and Luis Felipe Alvarez León, "The Logics and Territorialities of Geoblocking," in Geoblocking and Global Video Culture, ed. Ramon Lobato and James Meese (Amsterdam: Institute of Networked Cultures, 2016), 42-53.

${ }^{37}$ Brett Christophers, Envisioning Media Power: On Capital and Geographies of Television. Lanham, MD: Lexington Books, 2009; Bruce Owen and Steven Wildman, Video Economics. Cambridge, MA: Harvard University Press, 1992.

${ }^{38}$ Gillian Doyle, "Digitization and Changing Windowing Strategies in the Television Industry: Negotiating New Windows on the World," Television and New Media 7 (2016): 629-45; Jeff Ulin, The Business of Media Distribution: Monetizing film, TV and Video Content in an Online World (Abingdon: Focal Press, 2014).

${ }^{39}$ Doyle, "Digitization and Changing Windowing Strategies in the Television Industry"; Variety, "China Sets Day-and-date Releases for 'Transformers, 'Cars 3'," September 1, 2017, http://variety.com/2017/film/asia/china-release-dates-for-transformersdespicable-.

${ }^{40}$ Ulin, The Business of Media Distribution, 5.

${ }^{41}$ Doyle, "Digitization and Changing Windowing Strategies in the Television Industry."

${ }^{42}$ Forbes, "Korean Drama 'Descendants Of The Sun' Breaks Records Thanks to Chinese Investments," September 1, 2017, https://www.forbes.com/sites/johnkang/2016/ 04/05/korean-drama-descendants-of-the-sun-breaks-records-thanks-to-chineseinvestments /.

${ }^{43}$ Yue Wang, "China's Huace Acquires Stake in South Korea's Next Entertainment World," October 8, 2014, https://www.forbes.com/sites/ywang/2014/10/08/ chinas-huace-acquires-stake-in-south-koreas-next-entertainment-world/ \#540d33f0695e.

${ }^{44}$ Sina.com.cn, "Chinese Capital Pursuing Korean Wave," September 3, 2014, http:// finance.sina.com.cn/chanjing/cyxw/20140903/094420199178.shtml.

${ }^{45}$ Ulin, The Business of Media Distribution.

46 "Exclusive Interview with Yang Xianghua: Average Revenue per Subscription is 20 Times More than Average Advertising Revenue per User," October 16, 2015, http:// www.jiemian.com/article/406635.html.

47 iQiyi.com, "iQIYI Completes Convertible Bond Subscription and Continues to Build an Internet-driven Entertainment Empire," February 21, 2017, http://www.iqiyi .com/common/20170301/76b92b54e6c6106e.html.

48 iQiyi, "iQiyi Announces Paid Subscribers Exceeding 20 Million," June 14, 2016, https://www.prnewswire.com/news-releases/iqiyi-announces-paid-subscribersexceeding-20-million-300284271.html.

${ }^{49}$ Youjeong Oh, "The Interactive Nature of Korean TV dramas: Flexible Texts, Discursive Consumption, and Social Media," in Hallyu 2.0: The Korean Wave in the Age of Social Media, ed. Sangjoon Lee and Abé Mark Nornes (Ann Arbor: University of Michigan Press, 2015), 133-53. 
${ }^{50}$ Ibid.

${ }^{51}$ China Daily, "China Demands Licenses for Overseas Series Streaming," September 5, 2014, http://www.chinadaily.com.cn/china/2014-09/05/content_18556272.htm.

\section{Bibliography}

Ashraf, Cameran, and Luis Felipe Alvarez León. "The Logics and Territorialities of Geoblocking." In Geoblocking and Global Video Culture, edited by Ramon Lobato and James Meese, 42-53. Amsterdam: Institute of Networked Cultures, 2016.

Burroughs, Benjamin, and Adam Rugg. "Extending the Broadcast: Streaming Culture and the Problems of Digital Geographies." Journal of Broadcasting E Electronic Media 58, no. 3 (2014): 365-80.Christophers, Brett. Envisioning Media Power: On Capital and Geographies of Television. Lanham, MD: Lexington Books, 2009.

Doyle, Gillian. "Digitization and Changing Windowing Strategies in the Television Industry: Negotiating New Windows on the World." Television and New Media 17, no. 7 (2016): 629-45.Gold, Thomas. "Go With Your Feelings: Hong Kong and Taiwan Popular Culture in Greater China." The China Quarterly 136 (1993): 907-25.

Holt, Jennifer. "Regulating Connected Viewing: Media Pipelines and Cloud Policy." In Connected Viewing: Selling, Streaming, and Sharing Media in the Digital Era, edited by Jennifer Holt and Kevin Sanson, 19-39. New York: Routledge, 2014.

Holt, Jennifer, and Kevin Sanson. "Mapping Connections." In Connected Viewing: Selling, Streaming and Sharing Media in the Digital Era, edited by Jennifer Holt and Kevin Sanson, 1-16. New York: Routledge, 2014.

Iwabuchi, Koichi. Recentering Globalization: Popular Culture and Japanese Transnationalism. Durham and London: Duke University Press, 2002.

Keane, Michael. "Disconnecting, Connecting, and Reconnecting: How Chinese Television Found Its Way Out of the Box." International Journal of Communication 10 (2016): 5426-43.Keane, Michael, Brian Yecies, and Terry Flew, eds., Willing Collaborators: Foreign Partners in Chinese Media. London and New York: Rowman \& Littlefield, 2018.

Keane, Michael, and Elaine Jing Zhao. "The Reform of the Cultural System: Culture, Creativity and Innovation in China." In Cultural Policies in East Asia: Dynamics between the State, Arts, and Creative Industries, edited by Lee Hye-Kyung and Lorraine Lim, 155-73. Basingstoke: Palgrave Macmillan, 2014.

Kokas, Aynne. "American Media and China's Blended Public Sphere." In Connected Viewing: Selling, Streaming, E Sharing Media in the Digital Era, edited by Jennifer Holt and Kevin Sanson, 144-57. New York: Routledge, 2014.

Li, Jinying. "China: The Techno-Politics of the Wall." In Geoblocking and Global Video Culture, edited by Ramon Lobato and James Meese, 110-19. Amsterdam: Institute of Network Cultures, 2016.

MacKinnon, Rebecca."Networked authoritarianism in China and beyond: Implications for Global Internet Freedom." Journal of Democracy 2 (2011): 32-46. 
Oh, Youjeong. "The Interactive Nature of Korean TV Dramas: Flexible Texts, Discursive Consumption, and Social Media." In Hallyu 2.0: The Korean Wave in the Age of Social Media, edited by Sangjoon Lee and Abé Mark Nornes, 133-53. Ann Arbor: University of Michigan Press, 2015.Owen, Bruce, and Steven Wildman. Video Economics. Cambridge, MA: Harvard University Press, 1992.

Schiller, Dan. Digital Depression: Information Technology and Economic Crisis. Urbana.: University of Illinois Press, 2014.

Shambaugh, David. China Goes Digital: The Partial Power. Oxford: Oxford University Press, 2013.

Sinclair, John, Elizabeth Jacka, and Stuart Cunningham. New Patterns in Global Television: Peripheral Vision. Oxford: Oxford University Press, 1996.

Sinclair, John, Audrey Yue, Gay Hawkins, Kee Pookong, and Josephine Fox. "Chinese Cosmopolitanism and Media Use." In Floating Lives: The Media and Asian Diasporas, edited by Stuart Cunningham and John Sinclair, 1-34. St Lucia: University of Queensland Press, 2000.

Sun, Wanning. "Slow Boat from China: Public Discourses behind the "Going Global" Media Policy." International Journal of Cultural Policy 21, no. 4 (2015): 400-18.

Trimble, Marketa. "Geoblocking, Technical Standards and the Law." In Geoblocking and Global Video Culture, edited by Ramon Lobato and James Meese, 54-63. Amsterdam: Institute of Network Cultures, 2016.

Tseng, Bowen. "The Sunflower Movement: The Spatiality of Discursive Axes." Reflection 27 (2014): 129-48.Ulin, Jeff. The Business of Media Distribution: Monetizing Film, TV and Video Content in an Online World. Abingdon: Focal Press, 2014.

Voci, Paola. China on Video: Smaller-Screen Realities Oxon and New York: Routledge, 2010.

Wagman, Ira, and Peter Urquhart. "'This Content Is Not Available in Your Region': Geoblocking Culture in Canada." In Dynamic Fair Dealing: Creating Canadian Culture Online, edited by Darren Wershle, Coombe Rosemary, and Martin Zeilinger, 124-32. Toronto, ON: University of Toronto Press, 2014.

Wang, Chih-ming. "'The Future that Belongs to Us': Affective Politics, Neoliberalism and the Sunflower Movement." International Journal of Cultural Studies 20, no. 2 (2017): 177-92.

Zhao, Elaine Jing. "Collaboration Reconfigured: The Evolving Landscape of Entertainment TV Markets between Taiwan and Mainland China." Media International Australia 159, no. 1(2016): 53-62.Zhao, Elaine Jing. "Professionalization of Amateur Production in Online Screen Entertainment in China: Hopes, Frustrations and Uncertainties." International Journal of Communication 10 (2016): 5444-62.

Zhao, Elaine Jing. "Cross-Straits Online Collaboration: Multiple Publics and Intractable Institutions." In Willing Collaborators: Foreign Partners in Chinese Media, edited by Michael Keane, Brian Yecies, and Terry Flew, 189-200. London and New York: Rowman \& Littlefield, 2018.

Zhao, Elaine Jing, and Michael Keane. "Between Formal and Informal: The Shakeout in China's Online Video Industry." Media, Culture E Society 35, no. 6 (2013): 724-41. 